ARTICLE

DOI: $10.1038 / \mathrm{s} 41467-017-02061-7$

\title{
A modular synthesis of tetracyclic meroterpenoid antibiotics
}

\author{
Raphael Wildermuth ${ }^{1}$, Klaus Speck ${ }^{1}$, Franz-Lucas Haut ${ }^{1}$, Peter Mayer ${ }^{1}$, Bianka Karge ${ }^{2}$, Mark Brönstrup (i) ${ }^{2}$ \\ $\&$ Thomas Magauer ${ }^{1,3}$
}

Stachyflin, aureol, smenoqualone, strongylin A, and cyclosmenospongine belong to a family of tetracyclic meroterpenoids, which, by nature of their unique molecular structures and various biological properties, have attracted synthetic and medicinal chemists alike. Despite their obvious biosynthetic relationship, only scattered reports on the synthesis and biological investigation of individual meroterpenoids have appeared so far. Herein, we report a highly modular synthetic strategy that enabled the synthesis of each of these natural products and 15 non-natural derivatives. The route employs an auxiliary-controlled Diels-Alder reaction to enable the enantioselective construction of the decalin subunit, which is connected to variously substituted arenes by either carbonyl addition chemistry or sterically demanding $\mathrm{sp}^{2}-\mathrm{sp}^{3}$ cross-coupling reactions. The selective installation of either the cis- or trans-decalin stereochemistry is accomplished by an acid-mediated cyclization/isomerization reaction. Biological profiling reveals that strongylin A and a simplified derivative thereof have potent antibiotic activity against methicillin-resistant Staphylococcus aureus.

\footnotetext{
${ }^{1}$ Department of Chemistry and Pharmacy, Ludwig-Maximilians-University Munich Butenandtstraße 5-13, Munich 81377, Germany. ${ }^{2}$ Department of Chemical Biology, Helmholtz Centre for Infection Research and German Center for Infection Research (DZIF), Inhoffenstrasse 7, 38124 Braunschweig, Germany. ${ }^{3}$ Institute of Organic Chemistry and Center for Molecular Biosciences, University of Innsbruck, 6020 Innsbruck, Austria. Correspondence and requests for materials should be addressed to T.M. (email: thomas.magauer@uibk.ac.at)
} 
M eroterpenoids, which are derived from a mixed biosynthetic terpenoid pathway, display a broad spectrum of biological activities and are equipped with a wealth of structural complexity that originates from highly sophisticated biosynthetic pathways ${ }^{1-9}$. The structurally-related natural products stachyflin $(\mathbf{1})^{10}$, aureol $(\mathbf{2})^{8,11}$, smenoqualone $(3)^{12}$, strongylin A $(4)^{13}$, cyclosmenospongine $(5)^{14}$, and mamanuthaquinone $(6)^{15}$ constitute a unique subclass of polycyclic meroterpenoids that was previously harvested from marine and fungal sources. Since the first isolation of aureol in 1980, considerable interest has arisen to prepare these complex natural products by chemical synthesis and explore their biological activities. Despite the successful synthesis of individual members in a reasonable number of synthetic operations (10-27 linear steps), none of the reported routes ${ }^{16-24}$ has enabled a practical access to the whole family of these fascinating natural products (Fig. 1).

Although scattered reports have revealed the antiviral $(\mathbf{1}, \mathbf{2} \text {, and } \mathbf{4})^{10,13,25}$, anticancer $(\mathbf{2}, \mathbf{4}, \mathbf{5} \text {, and } \mathbf{6})^{13-15,26}$, and antibiotic $(2)^{27}$ activities of several members of these natural products, an exhaustive biological screen of 1-6 and fully synthetic derivatives is still unavailable. So far, only a preliminary structure-activity relationship (SAR) study of semi-synthetic analogs of stachyflin (1) has been reported, revealing that subtle modifications of the aromatic isoindolinone component have a drastic effect on the observed H1N1 activity ${ }^{28-32}$. Here, we address these limitations and describe a highly modular synthetic platform for the construction of six natural products and 15 fully synthetic molecules that were previously inaccessible using semi-synthesis. Biological profiling reveals that this class of meroterpenoids has potent antibiotic activity against methicillinresistant Staphylococcus aureus.

\section{Results}

Total synthesis of $(+)$-stachyflin (1). As illustrated in Fig. 2a, recent efforts by our group enabled a highly convergent and scalable route to the trans-decalin-containing natural product cyclosmenospongine (5). The developed synthesis proceeds via the intermediacy of 5-epi-aureol (9) and enabled production of $420 \mathrm{mg}$ of $\mathbf{5}$ in a single batch ${ }^{33}$. However, all efforts to adapt this strategy for the construction of the cis-decalin subunit of 1-4 were unsuccessful.

We envisioned the synthesis of $\mathbf{1 - 6}$ by employing the highly convergent strategy depicted in Fig. 2b. For the retrosynthetic analysis, 1-6 were first traced back to their protected forms I and II. The carbon-oxygen bond disconnection at C10 leads to the 5,6-dehydrodecalin precursor III, which would enable the crucial late-stage assembly of either the cis- (kinetic product) or trans-decalin (thermodynamic product) by an acid-promoted isomerization/cyclization sequence. This event sets the remaining two of four consecutive stereocenters. To account for maximum modularity and convergence, we opted to break down III further into the simple building blocks phenol $\mathbf{I V}$, diene $\mathbf{V}$, and tiglic acid-derived dienophile VI using a $\mathrm{sp}^{2}-\mathrm{sp}^{3}$ cross-coupling (or nucleophilic addition) and an exo-selective, auxiliary-controlled Diels-Alder reaction that was described in seminal work by Danishefsky ${ }^{34}$ and Minnaard ${ }^{35}$.

We began our investigations with the synthesis of stachyflin (1) which contains a rare isoindolinone subunit (Fig. $3 a)^{36}$. As initial efforts to construct intermediate $\mathbf{1 5}$ according to a previously reported protocol ${ }^{37}$ were low yielding and not reproducible on a large scale, we set out to develop a more robust route. Our synthesis begins with a solvent-free Alder-Rickert reaction between the dimedone-derived bis-trimethylsilyl enol ether $\mathbf{1 0}$ and dimethyl 2-butynedioate (DMAD) ${ }^{38}$ to afford resorcinol 11
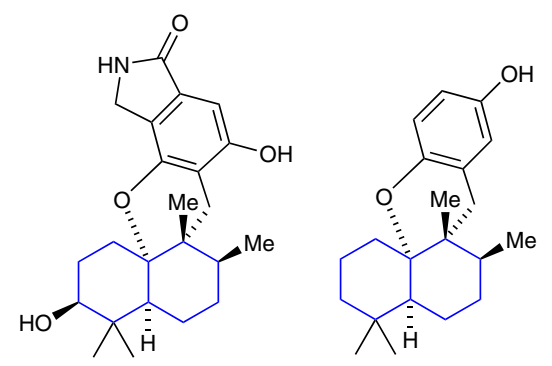

Stachyflin (1) [antiviral]

Aureol (2) [antiviral, antibiotic, cytotoxic]

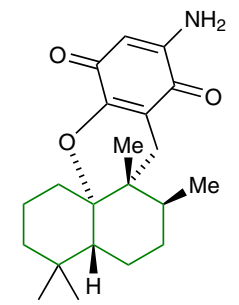

Strongylin A (4)

[antiviral, cytotoxic]
Cyclosmenospongine (5) [cytotoxic]

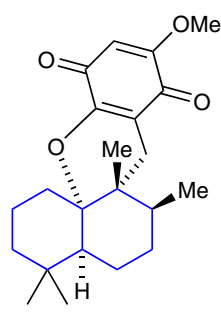

Smenoqualone (3) [not determined]

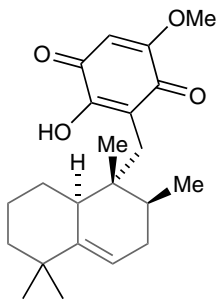

Mamanuthaquinone (6) [cytotoxic]
Fig. 1 Selected members of polycyclic meroterpenoids and their reported biological activity. Within this subclass of natural products, two distinct stereochemistries with respect to the decalin subunit have been noted. While compounds 1-4 possess a cis-decalin, cyclosmenospongine (5) features a unique trans-decalin scaffold. Both stereochemistries might biosynthetically originate from a 5,6-dehydrodecalin framework as present in mamanuthaquione (6). Color coding: blue, cis-decalin; green, transdecalin

(86\%). Careful monitoring of the reaction progress enables mono-methylation $\left(\mathrm{Me}_{2} \mathrm{SO}_{4}, \mathrm{~K}_{2} \mathrm{CO}_{3}\right.$, acetone) of 11 to furnish phenol $\mathbf{1 2}$ as a white crystalline solid in 73\% yield. Exposure of $\mathbf{1 2}$ to a solution of 3,4-dimethoxybenzylamine $\left(\mathrm{DMBNH}_{2}\right)$ and trimethylaluminum $\left(\mathrm{Me}_{3} \mathrm{Al}\right)$ effected clean conversion to the corresponding N,N-3,4-dimethoxydibenzyl phthalamide. The subsequent formation of imide $\mathbf{1 3}$ was induced by heating the neat phthalamide at $210^{\circ} \mathrm{C}$ under reduced pressure $(1 \mathrm{mbar})$ with simultaneous removal of the liberated $\mathrm{N}, \mathrm{N}$-3,4-dimethoxydibenzyl amine. While bromination $\left(\mathrm{Br}_{2}, \mathrm{CH}_{2} \mathrm{Cl}_{2}\right.$ or $\mathrm{Br}_{2}$, $\mathrm{AcOH})$ of 13 gave predominately the para-substituted phenol, exclusive formation of $\mathbf{1 4}$ occurred upon treatment with substoichiometric amounts of both iodine (0.6 equiv.) and periodic acid $(0.2 \text { equiv. })^{39}$. Treating a solution of $\mathbf{1 4}$ in tetrahydrofuran $(1.0 \mathrm{M})$ in a sealed tube with borane tetrahydrofuran complex (3.0 equiv.) and substoichiometric quantities of sodium borohydride $\left(0.05\right.$ equiv.) at elevated temperature $\left(70^{\circ} \mathrm{C}\right)$ effected regioselective reduction of the imide ${ }^{40}$. This protocol was crucial to obtain the product as a single regioisomer in high yield. Protection of the free phenol as its methoxymethyl ether completed the synthesis of isoindolinone $15(435 \mathrm{mg})$. The overall sequence to $\mathbf{1 5}$ proceeds in six steps and involves only crystalline intermediates, thus making it practical on a large scale.

We then focused on the construction of the 5,6-dehydrodecalin component 25 by employing Fan auxilliary-controlled exoselective Diels-Alder cycloadditon between diene 20 and tiglic acid-derived dienophile 21 (Fig. 3b).

Although the utility of $\mathbf{2 1}$ was previously demonstrated by Minnaard for the synthesis of 1-tuberculosinyl adenosine ${ }^{35}$, we were uncertain about the capability of $\mathbf{2 1}$ to override the inherent substrate selectivity of $\mathbf{2 0}$ and the extent of steric hindrance resulting from the benzyl ether at C3. Diene $\mathbf{2 0}$ was prepared from a known $\beta$-hydroxyketone $17^{41}$ via a three-step sequence involving 
$\mathbf{a}$

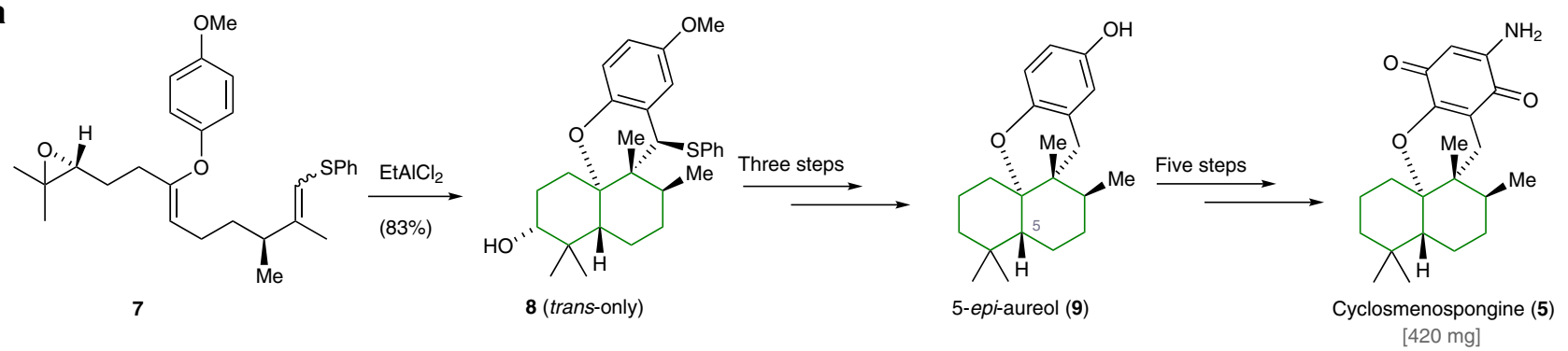

b
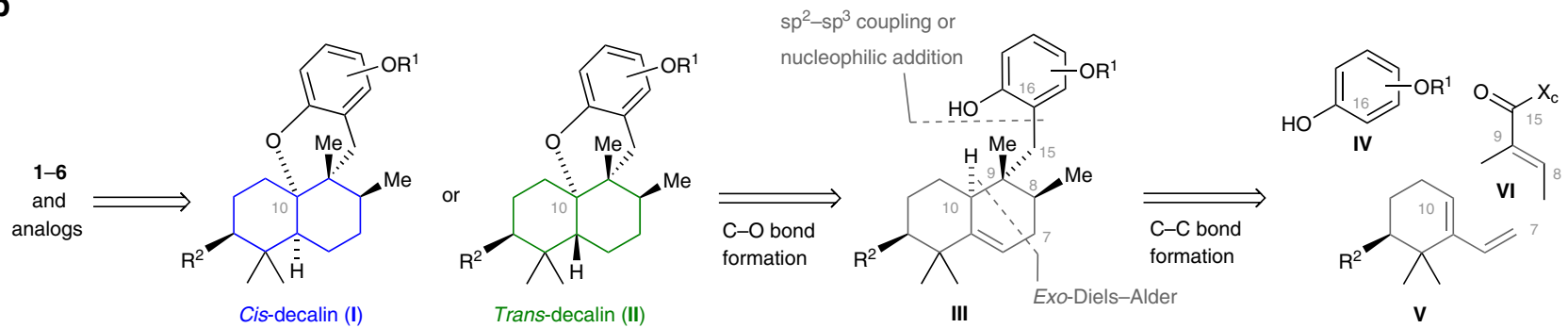

Fig. 2 Strategies for the construction of tetracyclic meroterpenoids. a The polyene cyclization reaction of aryl enol ether $\mathbf{7}$ enabled rapid assembly of the trans-decalin substructure of 5-epi-aureol (9) and cyclosmensopongine (5). However, this strategy could not be adapted for the preparation of meroterpenoids containing a cis-decalin subunit. $\mathbf{b}$ Synthesis of the 5,6-dehydrodecalin intermediate III should be accomplished by a highly modular, threecomponent coupling strategy of phenol IV , diene $\mathbf{V}$, and dienophile $\mathbf{V I}$. The ability to construct both cis- and trans-decalins from a common precursor would allow for the synthesis of 1-6 and a variety of non-natural derivatives for biological screening. Color coding: blue, cis-decalin, green, trans-decalin. $\mathrm{R}^{1}=\mathrm{alkyl}_{\mathrm{t}}$ $\mathrm{R}^{2}=\mathrm{H}$ or $\mathrm{OBn}, \mathrm{X}_{\mathrm{c}}=$ chiral auxiliary

the formation of the benzyl-protected ketone 18, conversion to the vinyltriflate 19, and Stille coupling (vinylSn $\left(n-\mathrm{Bu}_{3}\right), \operatorname{Pd}\left(\mathrm{PPh}_{3}\right)_{4}$, $\left.\mathrm{LiCl}, \mathrm{THF}, 75^{\circ} \mathrm{C}\right)$ to install the diene motif. Initial attempts to promote the reaction between $\mathbf{2 0}$ and $\mathbf{2 1}$ confirmed our concerns that 21 is reluctant to undergo cycloaddition under standard conditions $\left(\mathrm{Me}_{2} \mathrm{AlCl},\left(\mathrm{CH}_{2} \mathrm{Cl}\right)_{2},-40^{\circ} \mathrm{C}\right.$ to $\left.23^{\circ} \mathrm{C}\right)$. In order to overcome the low reactivity of 20 , we first subjected the reactants solution to high pressure $\left(14 \mathrm{kbar}, 23^{\circ} \mathrm{C}, \mathrm{Me}_{2} \mathrm{AlCl}, \mathrm{CH}_{2} \mathrm{Cl}_{2}\right)^{42}$. Although the formation of the desired Diels-Alder product 22 was observed under these forcing conditions, the product yield was low due to competing decomposition to an intractable mixture of products. However, the relative stereochemistry of 22 could be validated by single-crystal structure analysis. After further optimization, we found that $\mathbf{2 2}$ could be reproducibly obtained in a good yield and excellent diastereoselectivity $(\mathrm{dr}=13: 1)$ by conducting the cycloaddition in 1,2-dichloroethane in a sealed tube and slowly warming the reaction mixture from $-40^{\circ} \mathrm{C}$ to $23^{\circ} \mathrm{C}$. In this context, it is important to note that the chiral auxiliary fully overrides the substrate selectivity and the observed diastereoselectivity corresponds to the optical purity of $\mathbf{2 0}$ (83\% ee). Further conversion of 22 to iodide 25 via the intermediacy of thioester 23 and alcohol 24 proceeded smoothly to provide $2.3 \mathrm{~g}$ of 25 in a single batch.

With both components in hand, we turned our attention to the critical linkage of 15 to 25 (Fig. 4). This process was expected to be exceptionally challenging as it requires carbon-carbon bond formation between $\mathrm{C} 15$, which resides at a sterically hindered neopentylic position and C16, itself flanked by two alkyl ether substituents of the arene. From an evaluation of different coupling strategies and based on our recent success to realize challenging carbon-carbon bond formations ${ }^{43}$, a sp ${ }^{2}-\mathrm{sp}^{3}$ Negishi cross-coupling reaction ${ }^{44}$ emerged as the method of choice. To this end, we subjected both coupling partners to an exhaustive screen of reactions conditions (see Supplementary Table 1). We found that the coupling could be efficiently mediated by treating a solution of 25, Pd-SPhos G2 (20 mol\%), and SPhos (20 mol\%) ${ }^{44}$ in tetrahydrofuran and $N, N$-dimethylacetamide (2:1) with the organozinc species derived from 15. The use of $N, N$ - dimethylacetamide as a co-solvent and slightly elevated temperature $\left(40^{\circ} \mathrm{C}\right)$ were crucial to reproducibly observe full conversion, short reaction times, and acceptable yields (56\%).

Having prepared the 5,6-dehydrodecalin intermediate 26 $(330 \mathrm{mg})$, the stage was set to investigate the keytransformation for the installation of the cis-decalin framework. This step was inspired by a previous work on effect-related cascade cyclizations ${ }^{45}$ and was realized by first cleaving the methoxymethyl ether in $\mathbf{2 6}$. The so-formed phenol was unstable upon standing and therefore was directly exposed to boron trifluoride etherate at $-40{ }^{\circ} \mathrm{C}$. Slowly raising the temperature to $-15^{\circ} \mathrm{C}$ over a period of $1 \mathrm{~h}$ led to full consumption of the phenol. Although the mechanism of this cyclization reaction is still unclear, it may be that protonation of the alkene first affords the C5 carbocation 27. Whether this directly undergoes stereospecific 1,2-hydride shift to give the $\mathrm{C} 10$ carbocation 29 or involves the intermediacy of the $\mathrm{C} 5-\mathrm{C} 10$ alkene $\mathbf{2 8}$ is uncertain at this point. At temperatures below $-15^{\circ} \mathrm{C}$, trapping of the cation by the phenol is kinetically controlled to exclusively provide the cis-decalin. The use of the secondary benzyl-protecting group and maintaining temperatures below $-15^{\circ} \mathrm{C}$ proved to be essential to minimize ionization of the $\mathrm{C} 3$ position and undesirable ring contraction (see Supplementary Methods and Supplementary Fig. 61). Hydrogenolysis of the cyclization product facilitated purification and afforded 30 in $62 \%$ yield. For the completion of the synthesis of $\mathbf{1}$, the DMB group was removed oxidatively using previously reported conditions (PIFA, benzene) ${ }^{46}$. Finally, cleavage of the methyl ether with potassium $n$-dodecanethiolate $\left(n-\mathrm{C}_{12} \mathrm{H}_{24} \mathrm{SK}\right)$ in $\mathrm{N}, \mathrm{N}$-dimethylformamide (DMF) at $140{ }^{\circ} \mathrm{C}$ proceeded smoothly to afford (+)-stachyflin (1). Spectroscopic data $\left({ }^{1} \mathrm{H} \mathrm{NMR}{ }^{13}, \mathrm{C} \mathrm{NMR}\right.$, optical rotation) were found to be identical with those reported for natural $1^{10}$.

Total synthesis of natural products 2-6. Having established a convergent and scalable synthesis of tetracyclic meroterpenoids bearing a cis-fused decalin system, we set out to modify the route 
a

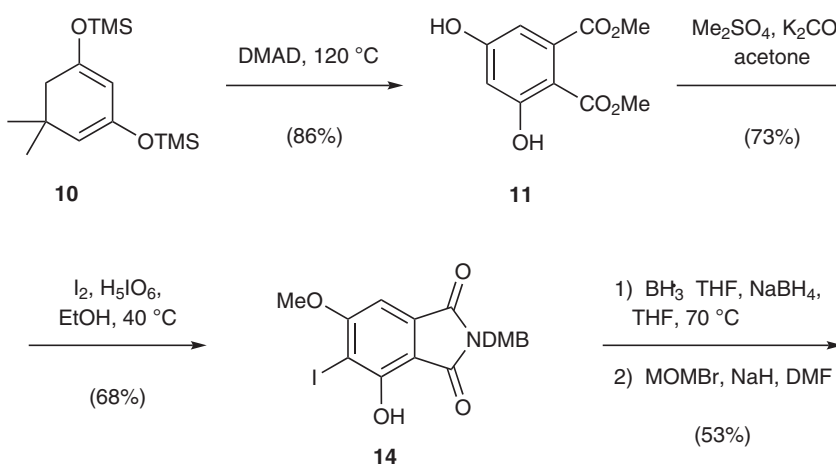

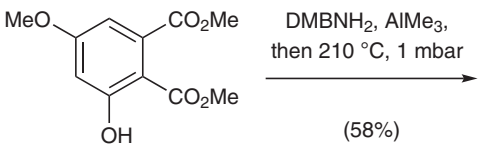

12<smiles>CCCCCCCN1C(=O)c2cc(OC)cc(O)c2C1=O</smiles>

13

b

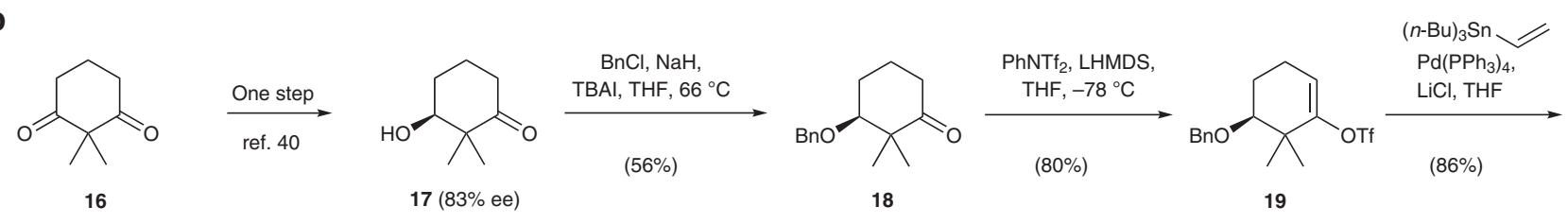

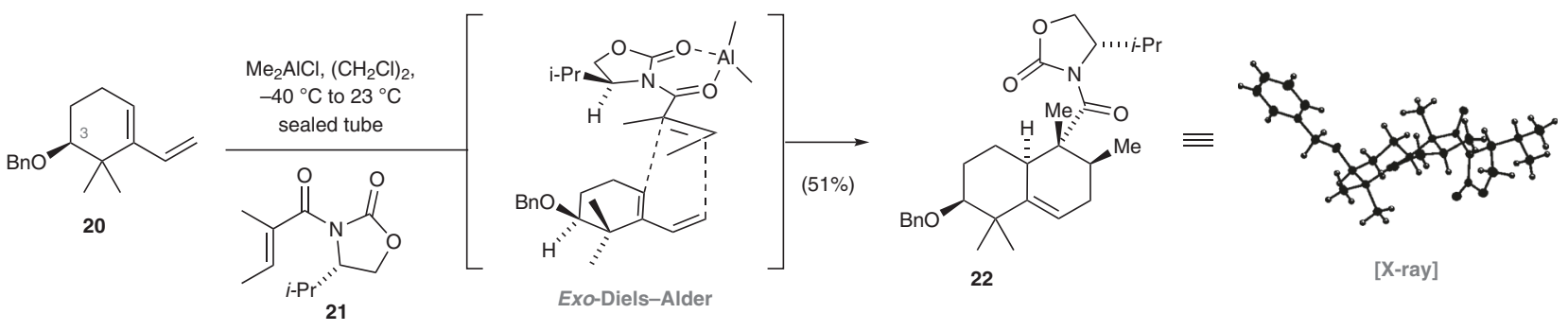

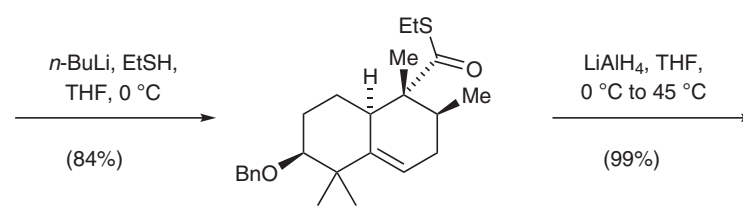

23

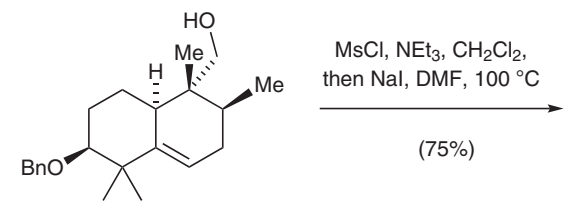

24<smiles>COc1cc2c(c(OC)c1I)CN(S(C)(=O)=O)C2=O</smiles>

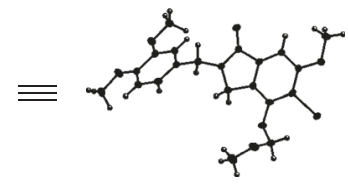

[X-ray]<smiles>CC(C)[C@@H]1CCC2C(=CC[C@@H](C)C2(C)C)[C@H]1C=[IH]</smiles>

$25[2.3 \mathrm{~g}]$

Fig. 3 Synthesis of the isoindolinone component $\mathbf{1 5}$ and the dehydrodecalin $\mathbf{2 5}$. a The developed de novo synthesis of isoindolinone $\mathbf{1 5}$ proceeds in six linear steps and only involves crystalline intermediates. b For the construction of the 5,6-dehydrodecalin $\mathbf{2 5}$, an auxiliary-controlled exo-selective Diels-Alder cycloaddition was employed. This allowed the production of $\mathbf{2 5}$ in eight steps in gram quantities in a single batch. DMAD dimethyl acetylenedicarboxylate, $n$-Bu n-butyl, Bn benzyl, DMB 3,4-dimethoxybenzyl, DMF N,N-dimethylformamide, LHMDS lithium hexadimethylsilazide, MOM methoxymethyl, Ms methanesulfonyl, TBAI tetrabutylammonium iodide, Tf trifluoromethanesulfonyl, THF tetrahydrofuran

in order to incorporate selective modifications and expand our library of natural and non-natural analogs. For the asymmetric synthesis of 2-6, which are derived from the common 3-deoxy5,6-dehydrodecalin subunit 33, we utilized the previously reported two-step sequence by Minnaard (Fig. 5) ${ }^{35}$. Thioester 32 underwent smooth Fukuyama reduction ${ }^{47}$ to give aldehyde 33, whose relative stereochemistry was validated by single-crystal structure analysis (see Supplementary Fig. 62). Pleasingly, the use of the less sterically demanding arene component $34^{48}$ enabled replacement of the previously required $\mathrm{sp}^{2}-\mathrm{sp}^{3}$ cross-coupling reaction and thus simplified the installation of the crucial C15-C16 carbon-carbon bond. The ortho-directed lithiation of 34 followed by 1,2-addition to $\mathbf{3 3}$ gave a mixture of diastereoisomeric benzyl alcohols. Application of the two-step Barton-McCombie deoxygenation protocol $\left(\mathrm{CS}_{2}, \mathrm{MeI}\right.$, NaHMDS, then AIBN, $\left.n-\mathrm{Bu}_{3} \mathrm{SnH}, 90^{\circ} \mathrm{C}\right)^{49}$ reproducibly provided 35 in good yield (72\%). For the completion of the synthesis of aureol (2), both methoxymethyl ethers of $\mathbf{3 5}$ were first cleaved upon exposure to hydrochloric acid in methanol. The resulting hydroquinone was prone to oxidation and therefore was not purified but directly subjected to the optimized cyclization conditions $\left(\mathrm{BF}_{3} \cdot \mathrm{OEt}_{2}, \mathrm{CH}_{2} \mathrm{Cl}_{2},-40^{\circ} \mathrm{C}\right.$ to $\left.-10^{\circ} \mathrm{C}\right)$ to afford $193 \mathrm{mg}$ of (+)-aureol (2) in a single batch. From there, the non-natural 5-epi-derivative 9 was prepared by thermal isomerization of the cis-decalin using hydroiodic acid in benzene at $90{ }^{\circ} \mathrm{C}(87 \%)^{50}$.

In addition, cyclosmenospongine (5) was accessible by subjecting 9 to our previously developed functionalization sequence $^{33}$. In a similar vein, mamanuthaquinone (6) was synthesized by the coupling between 33 and arene 36 to give 37. Compound $\mathbf{3 7}$ was deprotected and then oxidized (salcomine, $\mathrm{O}_{2}$ ) to give 6 , which slowly decomposed upon storage at $-20^{\circ} \mathrm{C}$. Having demonstrated the generality and versatility of the developed modular synthetic platform, further structural modifications could be efficiently made by simple variation of the arene and decalin component, and adjustment of the cyclization conditions. While kinetic conditions $\left(\mathrm{BF}_{3} \cdot \mathrm{OEt}_{2}\right.$, 
<smiles>CC1CC=C2C(CCC([18OH])C2(C)C)C1[14CH2]I</smiles>

25<smiles></smiles>

15
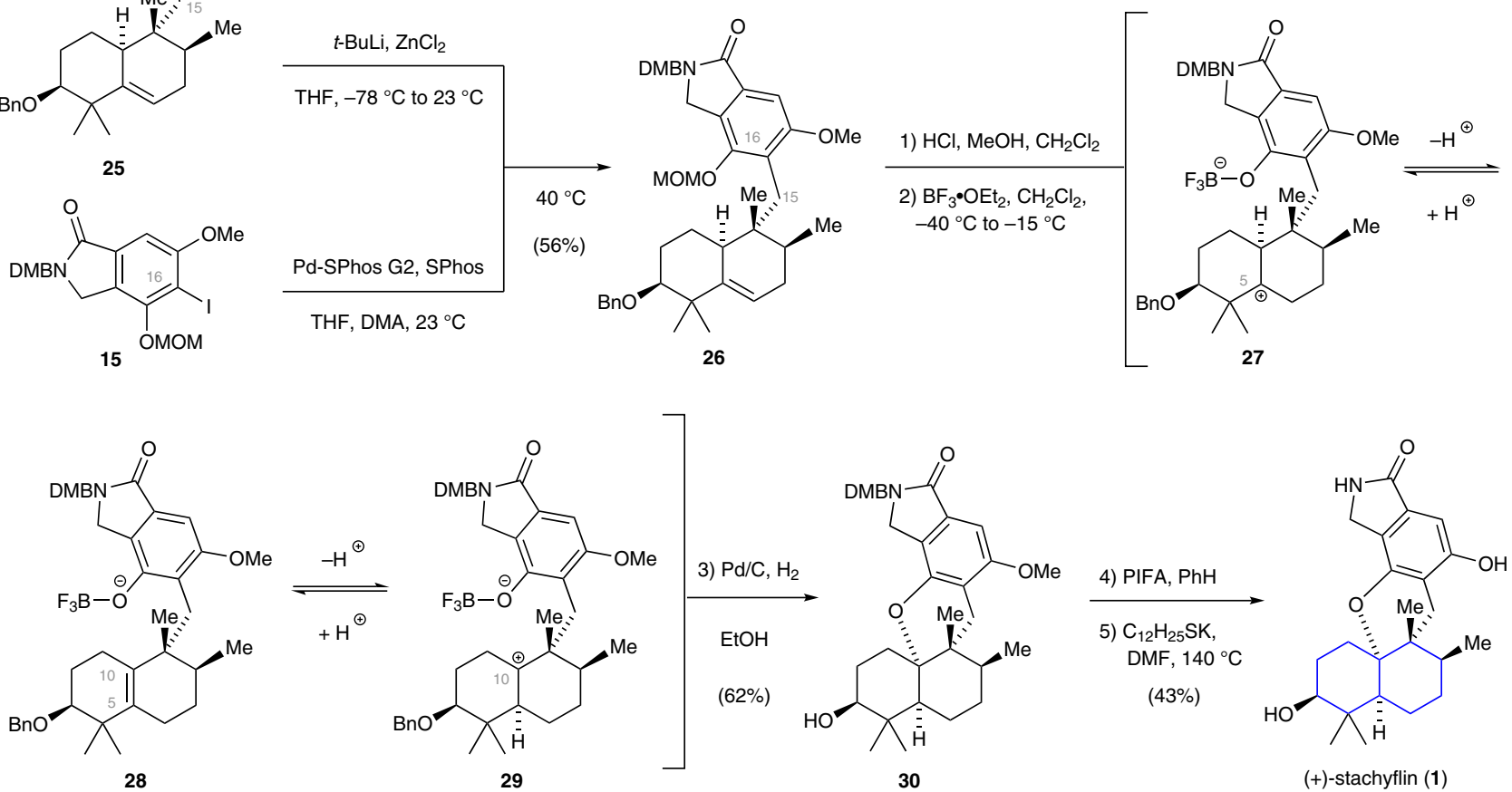

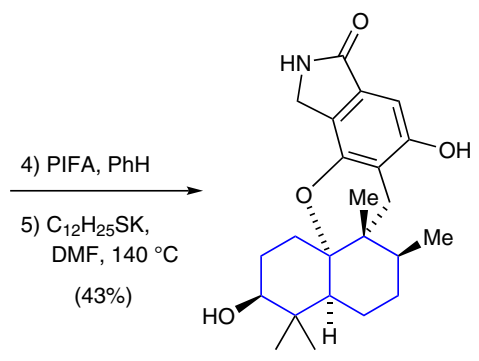

(+)-stachyflin (1)

Fig. 4 Component coupling and total synthesis of (+)-stachyflin (1). The $\mathrm{sp}^{2}-\mathrm{sp}^{3}$ Negishi cross-coupling reaction between arene $\mathbf{1 5}$ and iodide $\mathbf{2 5}$ provided the precursor for the intended cyclization reaction. Promotion of this step was accomplished by the addition of excess boron trifluoride etherate (10 equiv.) at low temperature $\left(-40^{\circ} \mathrm{C}\right)$ to exclusively produce the cis-decalin $\mathbf{3 0}$. At temperatures exceeding $-15^{\circ} \mathrm{C}$, competing ionization of the $\mathrm{C} 3$ position and ringcontraction prevailed (byproduct not shown, see Supplementary Methods). $t$-BuLi tert-butyllithium, DMA N,N-dimethylacetamide, PIFA phenyliodine bis (trifluoroacetate), SPhos 2-dicyclohexylphosphino-2', 6'-dimethoxybiphenyl, SPhos-Pd G2 chloro(2-dicyclohexylphosphino-2', 6'-dimethoxy-1,1'-biphenyl) [2-(2'-amino-1,1'-biphenyl)]palladium(II)

$\mathrm{CH}_{2} \mathrm{Cl}_{2},-40^{\circ} \mathrm{C}$ to $-10{ }^{\circ} \mathrm{C}$ ) gave the cis-decalin framework exclusively, equilibration under thermodynamic conditions (HI, benzene, $90^{\circ} \mathrm{C}$ ) afforded the trans-decalin as the only stereoisomer.

In this manner, $(+)$-smenoqualone (3) and (+)-strongylin A (4), and 15 fully synthetic tetracyclic analogs that were previously inaccessible via semi-synthesis could be prepared (Fig. 6 and Supplementary Methods). With the synthetic natural products 1-5 as well as the analogs 9 and $\mathbf{3 8 - 5 1}$ at hand, a basic phenotypic bioprofile of meroterpenoids was recorded in antibacterial and antiproliferative assays. Antimicrobial activities were tested against members of the ESKAPE panel ${ }^{51}$, consisting of the gram-positive bacteria methicillin-resistant Staphylococcus aureus (MRSA) and Enterococcus faecium, the gram-negative bacteria Escherichia coli, Pseudomonas aeruginosa, Acinetobacter baumannii, and Klebsiella pneumonia, and the yeast fungus Candida albicans. All compounds proved to be inactive against gram-negative pathogens and C. albicans. However, several analogs inhibited the growth of the MRSA-type strain DSM 11822 and the MRSA clinical isolate RKI 11-02670 with the following SARs (Fig. 6 and Supplementary Table 21): the highest activities were observed for $\mathbf{4 0}$, with $\mathrm{EC}_{50}$ values of 0.2 and 0.6 $\mu \mathrm{M}$ against DSM 11822 and RKI 11-02670, respectively, and for strongylin A (4), which was active with $\mathrm{EC}_{50}$ values of 1 and 1 $\mu \mathrm{M}$. Surprisingly, the combination of the heteroatom functionalities of $\mathbf{4}$ and $\mathbf{4 0}$ led to a pronounced drop of activity, as demonstrated by 3-hydroxy-strongylin $(\mathbf{4 8})(83 / 49 \mu \mathrm{M})$. Related compounds with 3-hydroxy function and a para-quinone unit like $\mathbf{4 9}$ or a heterocycle as found in stachyflin (1), 43 and $\mathbf{4 4}$ had also had little or no activity. In line with this, a non-hydroxylated, contracted cyclopentene ring, as present in the stachyflin analog 39 , led to re-gained activity $(6 / 8 \mu \mathrm{M})$. On the other hand, a lack of functionalities at the decalin and aromatic subunit also led to inactive compounds, as demonstrated by $\mathbf{4 1}$ and $\mathbf{4 2}$. While the mono-hydroxylated aureol 2 exhibited a potency $(5 / 5 \mu \mathrm{M})$ comparable to 4 , the oxidation of the methylated hydroquinone to a para-quinone as present in $\mathbf{4 6}$ was associated with a pronounced drop of anti-MRSA activity to $33 / 20 \mu \mathrm{M}$. A clear activity ranking for a cis- vs. trans-configuration of the decalin ring was not evident: the trans isomer was more potent in the $\mathbf{4 6}$ vs. $\mathbf{4 7}, 3$ vs. 51, and 5 vs. 50 pairs, while the opposite was true for the 4 vs. 45 and the 43 vs. 44 pairs. The antiproliferative activities of the compounds in the four mammalian cell lines L929, KB-3-1, MCF-7, and FS4-LTM were tested using a WST-1 assay that quantifies the metabolic activity of the cell population (Supplementary Table 22). The highest activities were observed for $\mathbf{4 0}$ $\left(\mathrm{EC}_{50}\right.$ values of $\left.7-14 \mu \mathrm{M}\right)$ and $49\left(\mathrm{EC}_{50}\right.$ values of $\left.8-21 \mu \mathrm{M}\right)$, both hydroxylated at the $\mathrm{C} 3$ position. The observation that the SAR did not parallel the antimicrobial activity suggests that a separation of antibiotic and cytotoxic activities is possible, and an even larger split may be obtained by further structural optimization.

\section{Discussion}

In summary, we established a highly modular and robust synthetic platform for the construction of variously substituted meroterpenoid scaffolds. Our efforts culminated in the enantioselective total syntheses of (+)-stachflin (1), (+)-aureol (2), $(+)$-smenoqualone (3), (+)-stronglin A (4), (-)-cyclosmenospongine (5), and (-)-mamanuthaquinone (6). Key steps include an asymmetric Diels-Alder reaction to install the 4,5-dehydrodecalin framework, either a highly efficient $\mathrm{sp}^{2}-\mathrm{sp}^{3}$-Negishi cross-coupling reaction or a nucleophilic addition reaction to 


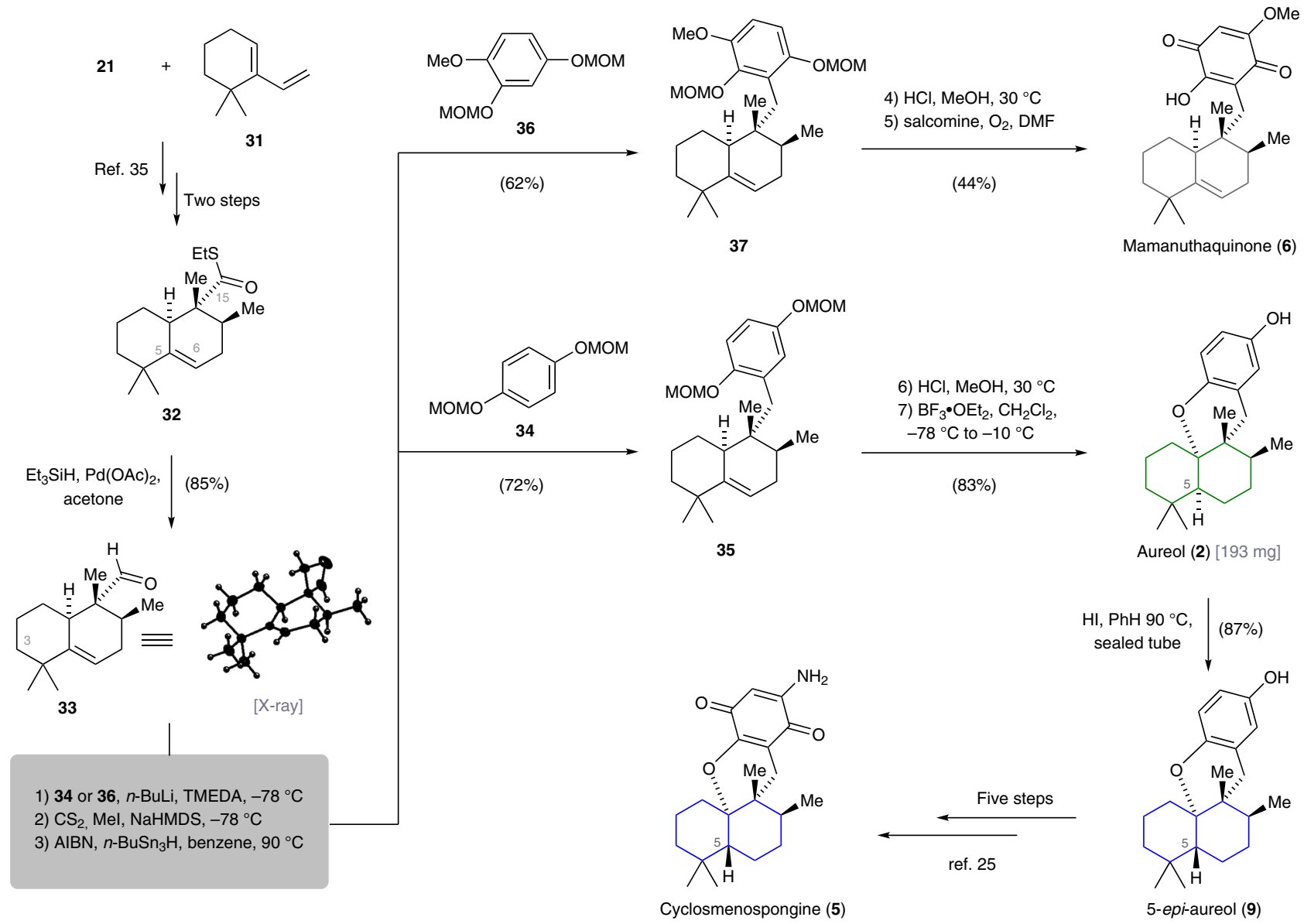

Fig. 5 Chemical synthesis of (+)-aureol (2), (-)-cyclosmenospongine (5), (-)-mamanuthaquinone (6), and (+)-5-epi-aureol (9). The 3-deoxy-5,6dehydrodecalin unit $\mathbf{3 3}$ was accessed in three steps from the known coupling of $\mathbf{2 1}$ and $\mathbf{3 1}$. Installation of the C15-C16 carbon-carbon bond was accomplished by ortho-directed lithiation of $\mathbf{3 4}$ or $\mathbf{3 6}$ and nucleophilic addition to $\mathbf{3 3}$. AIBN azobisisobutyronitrile, NaHMDS sodium hexadimethylsilazide, TMEDA $N, N, N, N^{\prime}$-tetramethylethylenediamine

forge the crucial C15-C16 carbon-carbon bond, and an acidmediated cyclization to selectively generate either stereoisomers of the decalin subunit. Simultaneous structural variation of more than one coupling component leads to rapid expansion of the compound library. The library of natural and fully synthetic molecules obtained so far was screened against a panel of bacterial pathogens and mammalian cell lines. Notably, the pronounced antibiotic activity of $\mathbf{4 0},(+)$-strongylin A (4), and $(+)$-aureol (2) against MRSA in the low- $\mu \mathrm{M}$ range appears promising. The reported SAR suggests that a further enhancement of activity is possible, e.g., through modifications at the aromatic ring, and such modifications enabled by the described synthetic platform.

\section{Methods}

NMR spectroscopy. NMR spectra were measured on a Bruker Avance III HD (400 MHz for proton nuclei, $100 \mathrm{MHz}$ for carbon nuclei) spectrometer equipped with a CryoProbe ${ }^{\mathrm{TM}}$, Bruker AXR300 $(300 \mathrm{MHz}$ for proton nuclei, $75 \mathrm{MHz}$ for carbon nuclei), Varian VXR400 S (400 MHz for proton nuclei, $100 \mathrm{MHz}$ for carbon nuclei), Bruker AMX600 (600 MHz for proton nuclei, $150 \mathrm{MHz}$ for carbon nuclei), or Bruker Avance HD $800(800 \mathrm{MHz}$ for proton nuclei, $200 \mathrm{MHz}$ for carbon nuclei). Proton chemical shifts are expressed in parts per million (ppm, $\delta$ scale) and the residual protons in the NMR solvent $\left(\mathrm{CHCl}_{3}, \delta=7.26 \mathrm{ppm} ; \mathrm{C}_{6} \mathrm{D}_{5} \mathrm{H}\right.$, $\delta=7.16 \mathrm{ppm}$; DMSO- $d 6, \delta=2.50 \mathrm{ppm}$ ) were used as internal reference. Carbon chemical shifts are expressed in parts per million ( $\delta$ scale, assigned carbon atom) and the residual solvent peaks $\left(\mathrm{CDCl}_{3}, \delta=77.16 \mathrm{ppm} ; \mathrm{C}_{6} \mathrm{D}_{6}, \delta=128.06 \mathrm{ppm}\right.$; DMSO- $d 6, \delta=39.52 \mathrm{ppm}$ ) were used as internal reference. The NMR spectroscopic data are reported as follows: chemical shift in ppm (multiplicity, coupling constants $J(\mathrm{~Hz})$, integration intensity) for ${ }^{1} \mathrm{H}$ NMR spectra and chemical shift in ppm for
${ }^{13} \mathrm{C}$ NMR spectra. Multiplicities are abbreviated as s (singlet), br s (broad singlet), $\mathrm{d}$ (doublet), $\mathrm{t}$ (triplet), $\mathrm{q}$ (quartet), and $\mathrm{m}$ (multiplet). Signals in the NMR spectra were assigned by the information obtained from 2D NMR experiments: homonuclear correlation spectroscopy (COSY), total correlation spectroscopy (TOCSY), heteronuclear single quantum coherence (HSQC), and heteronuclear multiple bond coherence (HMBC). The software MestReNOVA 11.0 from Mestrelab Research S. L was used to analyze and process all raw fid files.

Mass spectrometry. High resolution mass spectra (HRMS) were measured at the Department of Chemistry, Ludwig-Maximilians-University Munich, on the following instruments by electron impact (EI) or electron spray (ESI) techniques: MAT 95 (EI) and MAT 90 (ESI) from Thermo Finnigan GmbH.

IR spectroscopy. Infrared spectra (IR) were recorded on a PerkinElmer Spectrum BX II FT-IR system from 4000 to $600 \mathrm{~cm}^{-1}$. Substances were directly applied on the ATR unit as a thin film or a thin powder layer. The data are represented as frequency of absorption $\left(\mathrm{cm}^{-1}\right)$.

Optical rotation. Optical rotation values were recorded on a PerkinElmer 241 or Anton Paar MCP 200 polarimeter. The specific rotation is calculated as follows: $[\alpha]_{\lambda}^{\varphi}=[\alpha] \cdot 100 \cdot c^{-1} \cdot d^{-1}$. The wave length $\lambda$ is reported in $\mathrm{nm}$ (sodium $\mathrm{D}$ line, $\lambda$ $=589 \mathrm{~nm}$ ), the measuring temperature $\phi$ in ${ }^{\circ} \mathrm{C} ; \alpha$ represents the recorded optical rotation, $c$ the concentration of the analyte in $\mathrm{g} \mathrm{mL}^{-1}$, and $d$ the length of the cuvette in $\mathrm{dm}$. Thus, the specific rotation is given in $10^{-1} \mathrm{deg} \mathrm{cm}^{2} \mathrm{~g}^{-1}$. The values for the specific rotation are reported as follows: specific rotation (concentration $\mathrm{g} 100 \mathrm{~mL}^{-1}$; solvent).

Melting points. Melting points were determined on a B- 450 melting point apparatus from BÜCHI Labortechnik AG. 


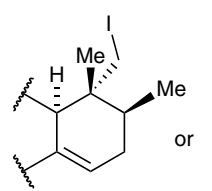

25

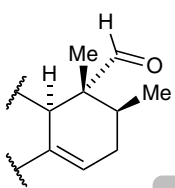

33

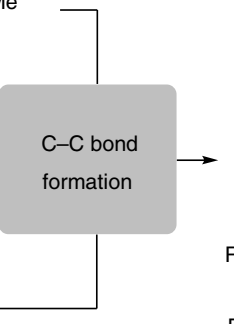

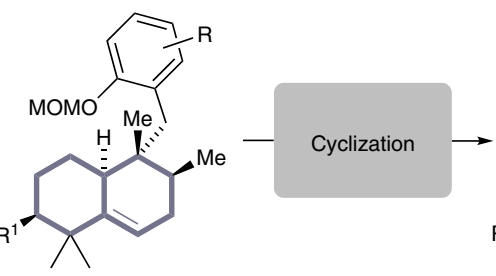

$\mathrm{R}^{1}=\mathrm{OBn}, \mathrm{H}$

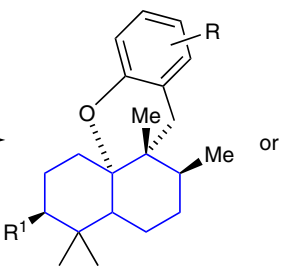

Cis-decalin (I)

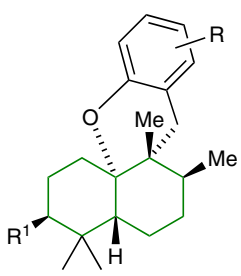

Trans-decalin (II)<smiles>Cc1c(O)cc2c(c1O[C@]13CC[C@@H](O)C(C)(C)C1CC[C@H](C)C3(C)C)CNC2=O</smiles>

(+)-stachyflin (1)

$\mathrm{EC}_{50}(\mathrm{MRSA})=>100 />100$<smiles>C[C@H]1CC[C@H]2C(C)(C)[C@@H](O)CC[C@]23Oc2ccccc2C[C@]13C</smiles>

40

$\mathrm{EC}_{50}(\mathrm{MRSA})=0.2 / 0.6$

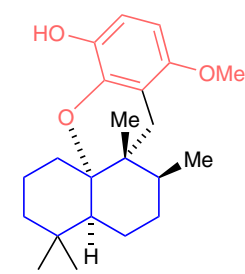

Strongylin A (4) $\mathrm{EC}_{50}(\mathrm{MRSA})=1 / 1$

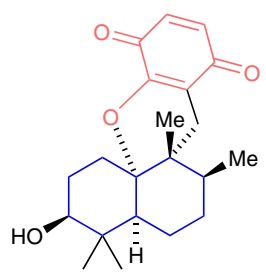

49

$\mathrm{EC}_{50}(\mathrm{MRSA})=77 / 75$

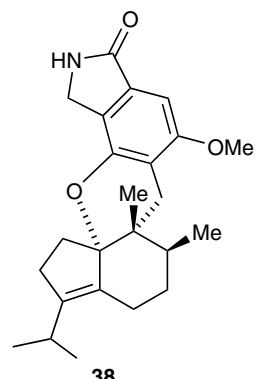

$\mathrm{EC}_{50}(\mathrm{MRSA})=6 / 8$

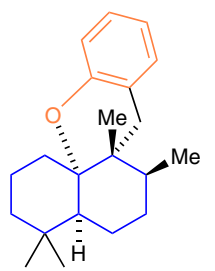

41

$\mathrm{EC}_{50}(\mathrm{MRSA})=>100 />100$

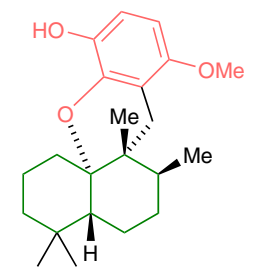

5-epi-strongylin A (45) $\mathrm{EC}_{50}(\mathrm{MRSA})=3 / 6$

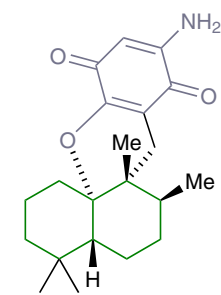

Cyclosmenospongine (5) $\mathrm{EC}_{50}(\mathrm{MRSA})=6 / 12$<smiles>Cc1c(O)cc2c(c1O[C@]13CCC(C(C)C)=C1CCC(C)C3(C)C)CNC2=O</smiles>

$\mathrm{EC}_{50}(\mathrm{MRSA})=6 / 8$

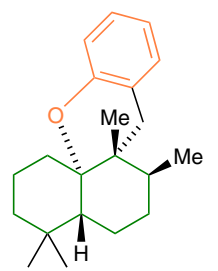

42

$\mathrm{EC}_{50}(\mathrm{MRSA})=>100 />100$

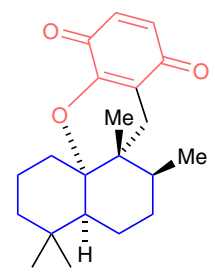

46

$\mathrm{EC}_{50}(\mathrm{MRSA})=33 / 20$

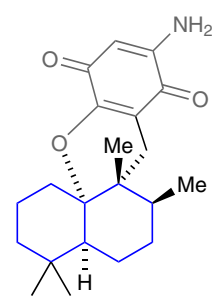

5-epi-cyclosmenospongine (50) $\mathrm{EC}_{50}(\mathrm{MRSA})=53 / 28$

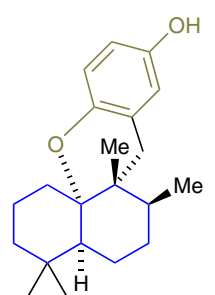

Aureol (2) $\mathrm{EC}_{50}(\mathrm{MRSA})=5 / 5$<smiles>Cc1ncccc1O[C@]12CCCC(C)(C)[C@H]1CC[C@@H](C)C2(C)C</smiles>

43 $\mathrm{EC}_{50}(\mathrm{MRSA})=70 / 9$

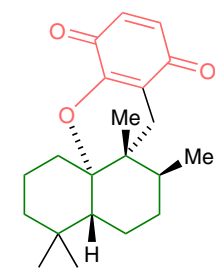

47

$\mathrm{EC}_{50}(\mathrm{MRSA})=15 / 15$

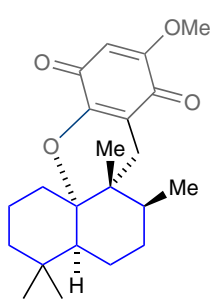

Smenoqualone (3) $\mathrm{EC}_{50}(\mathrm{MRSA})=22 / 22$

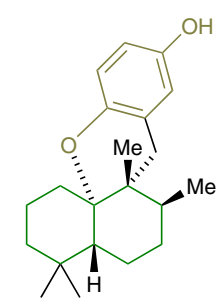

5-epi-aureol (9) $\mathrm{EC}_{50}(\mathrm{MRSA})=8 / 6$<smiles>Cc1ncccc1O[C@]12CCCC(C)(C)[C@]1(C)CC[C@@H](C)C2(C)C</smiles>

44

$\mathrm{EC}_{50}(\mathrm{MRSA})=>100 />100$<smiles>COc1ccc(O)c(O[C@]23CC[C@@H](O)C(C)(C)[C@H]2CC[C@@H](C)C3(C)C)c1C</smiles>

3-hydroxy strongylin A (48) $\mathrm{EC}_{50}(\mathrm{MRSA})=83 / 49$

5-epi-smenoqualone (51) $\mathrm{EC}_{50}(\mathrm{MRSA})=31 / 49$

Fig. 6 Extension of the modular synthetic platform. Structural variation of the arene and decalin component enabled rapid extension of the natural products library and provided access to several non-natural analogs that were previously inaccessible via semi-synthesis. Each of the shown molecules depicted was prepared in seven or fewer steps starting from iodide $\mathbf{2 5}$ or aldehyde 33. Color coding was used to indicate the decalin stereochemistry (coding: blue, cis-decalin; green, trans-decalin) and to highlight the modified arene component. The effective concentrations (EC 50 values) that inhibited the growth of two MRSA strains (DSM 11822/RKI 11-02670) are given in $\mu$ M 
Data availability. CCDC 1534418 (15), 1534416 (22), and 1534618 (33) contain the supplementary crystallographic data for this paper. These data can be obtained free of charge from the Cambridge Crystallographic Data Centre. The authors declare that all the data supporting the findings of this study are available within the article (and its supplementary information files).

Received: 1 August 2017 Accepted: 2 November 2017

Published online: 12 December 2017

\section{References}

1. Baunach, M., Franke, J. \& Hertweck, C. Terpenoid biosynthesis off the beaten track: unconventional cyclases and their impact on biomimetic synthesis. Angew. Chem. Int. Ed. 54, 2604-2626 (2015).

2. Christianson, D. W. Structural biology and chemistry of the terpenoid cyclases. Chem. Rev. 106, 3412-3442 (2006).

3. Hertweck, C. The biosynthetic logic of polyketide diversity. Angew. Chem. Int. Ed. 48, 4688-4716 (2009).

4. Cornforth, J. W. Terpenoid biosynthesis. Chem. Ber. 4, 102-106 (1968).

5. Capon, R. J. The acid-catalyzed rearrangement and absolute stereochemistry of isospongiaquinone. J. Nat. Prod. 53, 753-756 (1990).

6. Lakshmi, V., Gunasekera, S. P., Schmitz, F. J., Ji, X. \& Van der Helm, D. Acid-catalyzed rearrangement of arenerol. J. Org. Chem. 55, 4709-4711 (1990).

7. Paul, M. D. Medicinal Natural Products: A Biosynthetic Approach 2nd edn (Wiley, Chichester, 2002).

8. Djura, P. et al. Some metabolites of the marine sponges Smenospongia aurea and Smenospongia (polyfibrospongia) echina. J. Org. Chem. 45, 1435-1441 (1980).

9. Urban, S. \& Capon, R. J. Marine sesquiterpene quinones and hydroquinones: acid-catalysed rearrangements and stereochemical investigations. Aust. J. Chem. 47, 1023-1029 (1994).

10. Minagawa, K. et al. Stachyflin and acetylstachyflin, novel anti-influenza A virus substances, produced by stachybotrys sp. RF-7260. J. Antibiot. 55, 155-164 (2002).

11. Ciminiello, P., Aversano, C. D., Fattorusso, E., Magno, S. \& Pansini, M. Chemistry of verongida sponges. Secondary metabolite composition of the Caribbean sponge Verongula gigantea. J. Nat. Prod. 63, 263-266 (2000).

12. Bourguet-Kondracki, M.-L., Martin, M.-T. \& Guyot, M. Smenoqualone a novel sesquiterpenoid from the marine sponge Smenospongia sp. Tetrahedron Lett. 33, 8079-8080 (1992).

13. Wright, A. E., Rueth, S. A. \& Cross, S. S. An antiviral sesquiterpene hydroquinone from the marine sponge Strongylophora hartmani. J. Nat. Prod. 54, 1108-1111 (1991).

14. Utkina, N. K., Denisenko, V. A., Scholokova, O. V., Virovaya, M. V. \& Prokof eva, N. G. Cyclosmenospongine, a new sesquiterpenoid aminoquinone from an Australian marine sponge Spongia sp. Tetrahedron Lett. 44, 101-102 (2003).

15. Swersey, J. C., Barrows, L. R. \& Ireland, C. M. Mamamuthaquinone: an antimicrobial and cytotoxic metabolite of Fasciospongia sp. Tetrahedron Lett. 32, 6687-6690 (1991)

16. Watanabe, K., Sakurai, J., Abe, H. \& Katoh, T. Total synthesis of (+)-stachyflin: a potential anti-influenza A virus agent. Chem. Commun. 46, 4055-4057 (2010).

17. Taishi, T., Takechi, S. \& Mori, S. First total synthesis of ( \pm )-stachyflin. Tetrahedron Lett. 39, 4347-4350 (1998)

18. Sakurai, J., Kikuchi, T., Takahashi, O., Watanabe, K. \& Katoh, T. Enantioselective total synthesis of (+)-stachyflin: a potential anti-influenza A virus agent isolated from a microorganism. Eur. J. Org. Chem. 2011. 2948-2957 (2011).

19. Nakamura, M. et al. An efficient synthesis of $(+)$-aureol via boron trifluoride etherate-promoted rearrangement of $(+)$-arenarol. Tetrahedron Lett. 43, 6929-6932 (2002)

20. Rosales, A. et al. Synthesis of ( \pm )-aureol by bioinspired rearrangements. J. Org. Chem. 80, 1866-1870 (2015).

21. Marcos, I. S. et al. Synthesis of quinone/hydroquinone sesquiterpenes. Tetrahedron 66, 8280-8290 (2010).

22. Kuan, K. K. W., Pepper, H. P., Bloch, W. M. \& George, J. H. Total synthesis of (+)-aureol. Org. Lett. 14, 4710-4713 (2012).

23. Kamishima, T., Kikuchi, T. \& Katoh, T. Total synthesis of (+)-strongylin A, a rearranged sesquiterpenoid hydroquinone from a marine sponge. Eur. J. Org. Chem. 2013, 4558-4563 (2013).

24. Katoh, T., Atsumi, S., Saito, R., Narita, K. \& Katoh, T. Unified synthesis of the marine sesquiterpene quinones $(+)$-smenoqualone, (-)-Ilimaquinone, $(+)$-smenospongine, and (+)-sospongiaquinone. Eur. J. Org. Chem. 2017, 3837-3849 (2017).
25. Wright, A. E., Cross, S. S., Burres, Neal, S. \& Koehn, F. Novel antiviral and antitumor terpene hydroquinones and methods of use. US patent 5,051,519 (1990).

26. Mani, L. et al. New antiplasmodial bromotyrosine derivatives from Suberea ianthelliformis Lendenfeld, 1888. Chem. Biodivers. 9, 1436-1451 (2012).

27. $\mathrm{Hu}$, J. et al. New antiinfective and human 5-HT2 receptor binding natural and semisynthetic compounds from the Jamaican sponge Smenospongia aurea. J. Nat. Prod. 65, 476-480 (2002).

28. Motohashi, Y. et al. Antiviral activity of stachyflin on influenza A viruses of different hemagglutinin subtypes. Virol. J. 10, 118 (2013).

29. Yagi, S. et al. Development of anti-influenza virus drugs I: improvement of ora absorption and in vivo anti-influenza activity of stachyflin and its derivatives. Pharm. Res. 16, 1041-1046 (1999).

30. Yoshimoto, J. et al. Development of anti-influenza drugs: II. Improvement of oral and intranasal absorption and the anti-influenza activity of stachyflin derivatives. J. Pharm. Pharmacol. 52, 1247-1255 (2000).

31. Yoshimoto, J. et al. Identification of a novel HA conformational change inhibitor of human influenza virus. Arch. Virol. 144, 865-878 (1999).

32. Yanagita, H. et al. Mechanism of drug resistance of hemagglutinin of influenza virus and potent scaffolds inhibiting its function. ACS Chem. Biol. 7, 552-562 (2012)

33. Speck, K., Wildermuth, R. \& Magauer, T. Convergent assembly of the tetracyclic meroterpenoid (-)-cyclosmenospongine by a non-biomimetic polyene cyclization. Angew. Chem. Int. Ed. 55, 14131-14135 (2016).

34. Yoon, T., Danishefsky, S. J. \& de Gala, S. A concise total synthesis of $( \pm)$-mamanuthaquinone by using an exo-Diels-Alder reaction. Angew. Chem Int. Ed. 33, 853-855 (1994).

35. Buter, J. et al. Stereoselective synthesis of 1-tuberculosinyl adenosine; a virulence factor of Mycobacterium tuberculosis. J. Org. Chem. 81, 6686-6696 (2016).

36. Speck, K. \& Magauer, T. The chemistry of isoindole natural products. Beilstein J. Org. Chem. 9, 2048-2078 (2013).

37. Inoue, S., Kim, R., Hoshino, Y. \& Honda, K. Synthesis of tricyclic pyrano[2,3-e] isoindolin-3-ones as the core structure of stachybotrin A, B, and C. Chem. Commun. 0, 1974-1976 (2006).

38. Quintiliano, S. A. P. \& Silva, L. F. Practical synthesis of a functionalized 1-oxo1,2,3,4-tetrahydroisoquinoline-3-carboxylic acid. Tetrahedron Lett. 53, 3808-3810 (2012).

39. Ende, C. W., Zhou, Z. \& Parker, K. A. Total synthesis of ( \pm )-bisabosqual A. J. Am. Chem. Soc. 135, 582-585 (2013).

40. Saito, S., Ishikawa, T., Kuroda, A., Koga, K. \& Moriwake, T. A revised mechanism for chemoselective reduction of esters with borane-dimethyl sulfide complex and catalytic sodium tetrahydroborate directed by adjacent hydroxyl group. Tetrahedron 48, 4067-4086 (1992).

41. Yeung, Y. Y., Chein, R. J. \& Corey, E. J. Conversion of Torgov's synthesis of estrone into a highly enantioselective and efficient process. J. Am. Chem. Soc. 129, 10346-10347 (2007).

42. Hugelshofer, C. L. \& Magauer, T. High-pressure transformations in natural product synthesis. Synthesis 46, 1279-1296 (2014).

43. Speck, K. \& Magauer, T. Evolution of a polyene cyclization cascade for the total synthesis of (-)-cyclosmenospongine. Chem. Eur. J. 23, 1157-1165 (2016).

44. Thaler, T. et al. Highly diastereoselective $\mathrm{Csp}^{3}-\mathrm{Csp}^{2}$ Negishi cross-coupling with 1,2-, 1,3- and 1,4-substituted cycloalkylzinc compounds. Nat. Chem. 2, 125-130 (2010).

45. Katoh, T. Total synthesis of decahydrobenzo[d]xanthene sesquiterpenoids aureol, strongylin A, and stachyflin: development of a new strategy for the construction of a common tetracyclic core structure. Heterocycles 87, 2199-2223 (2013).

46. Watanabe, K., Shibata, H., Imai, Y. \& Katoh, T. Deprotection of 3,4dimethoxybenzyl $\left({ }^{3,4} \mathrm{DMB}\right)$ group on $\gamma$-lactam nitrogen using phenyliodine(III) bis(trifluoroacetate) (PIFA): application to isoindolinone compounds. Heterocycles 84, 1355-1361 (2012).

47. Fukuyama, T., Lin, S. C. \& Li, L. Facile reduction of ethyl thiol esters to aldehydes: application to a total synthesis of (+)-neothramycin A methyl ether. J. Am. Chem. Soc. 112, 7050-7051 (1990).

48. Shi, Z. F., Wang, L. J., Wang, H., Cao, X. P. \& Zhang, H. L. Synthesis of oligo (phenylene ethynylene)s with dendrimer 'shells' for molecular electronics. Org. Lett. 9, 595-598 (2007)

49. Barton, D. H. R. \& McCombie, S. W. A new method for the deoxygenation of secondary alcohols. J. Chem. Soc. Perkin Trans. 1, 1574-1585 (1975).

50. Marcos, I. et al. Chemistry of ent-halimic acid: synthesis of [4.3.3]propellanes. Synthesis 2006, 3865-3873 (2006).

51. Pendleton, J. N., Gorman, S. P. \& Gilmore, B. F. Clinical relevance of the ESKAPE pathogens. Expert Rev. Anti. Infect. Ther. 11, 297-308 (2013). 


\section{Acknowledgements}

T.M. acknowledges the German Research Foundation (Emmy Noether Project MA5999/ 2-1), the European Research Council under the European Union's Horizon 2020 research and innovation program (grant agreement No 714049) and the Funds of the Chemical Industry (Sachkostenzuschuss and Dozentenpreis). We thank Dr. Kevin Mellem

(Revolution Medicines) and Dr. Bryan Matsuura (LMU Munich) for helpful discussions.

\section{Author contributions}

R.W., K.S., F.-L.H., and T.M. conceived the synthetic route. R.W., K.S., F.-L.H., and B.K. conducted all experimental work and analyzed the results. R.W., M.B., and T.M. analyzed the data and wrote the manuscript.

\section{Additional information}

Supplementary Information accompanies this paper at https://doi.org/10.1038/s41467017-02061-7.

Competing interests: The authors declare no competing financial interests.

Reprints and permission information is available online at http://npg.nature.com/ reprintsandpermissions/
Publisher's note: Springer Nature remains neutral with regard to jurisdictional claims in published maps and institutional affiliations.

(c) (i) Open Access This article is licensed under a Creative Commons Attribution 4.0 International License, which permits use, sharing, adaptation, distribution and reproduction in any medium or format, as long as you give appropriate credit to the original author(s) and the source, provide a link to the Creative Commons license, and indicate if changes were made. The images or other third party material in this article are included in the article's Creative Commons license, unless indicated otherwise in a credit line to the material. If material is not included in the article's Creative Commons license and your intended use is not permitted by statutory regulation or exceeds the permitted use, you will need to obtain permission directly from the copyright holder. To view a copy of this license, visit http://creativecommons.org/ licenses/by/4.0/.

(C) The Author(s) 2017 